\title{
A TRADIÇÃO FÁUSTICA E A TRAGÉDIA SUBJETIVA NO FAUSTO DE FERNANDO PESSOA
}

\section{THE FAUST TRADITION AND THE SUBJECTIVE TRAGEDY OF FERNANDO PESSOA'S FAUST}

Rafael Rocca dos SANTOS 1

Resumo: A tradição fáustica, como mito do individualismo moderno, é um dos temas mais profícuos da literatura ocidental. Iniciada no século XVI, a temática de Fausto deu origem a centenas de narrativas e peças teatrais que continuam a ser escritas e encenadas. Tendo em vista a abrangência e a relevância da temática, este artigo traça um panorama histórico dos principais textos sobre Fausto desde o século XVI até o romantismo, construindo o que aqui se denomina tradição fáustica. Além da introdução da temática fáustica em Portugal, analisam-se as modificações operadas na tradição naquele que pode ser lido como o Fausto moderno por excelência, o Fausto de Fernando Pessoa, designado pelo autor como sua "tragédia subjetiva".

Palavras-chave: Fausto. Mito. Goethe. Fernando Pessoa. Tragédia.
Abstract: The Faust tradition, as a myth of modern individualism, is one of the main topics of the Western literary tradition. It began in the $16^{\text {th }}$ Century and gave rise to hundreds of narratives and plays which continue to be written and performed to this day. In view of the breadth and the relevance of this theme, this study presents a historical panorama of the main Faust texts from the $16^{\text {th }}$ Century to Romanticism, defining what is here called "Faustian tradition". In addition to the introduction of this theme in Portugal, this study analyses the changes in the tradition as expressed in a work that can be called the modern Faust par excellence: Faust, by Fernando Pessoa, entitled by the author as a "subjective tragedy".

Keywords: Faust. Myth. Goethe. Fernando Pessoa. Tragedy.

1 Universidade de São Paulo (USP), São Paulo, São Paulo, Brasil; rocca@usp.br; https://orcid.org/0000-0003-3783-1302 


\section{Introdução}

Iniciada na Alemanha do século XVI, a tradição fáustica se tornou um dos temas mais fecundos na história da literatura. Tratado por dezenas de autores desde seu início em 1587, o mito fáustico se desenvolveu em paralelo à evolução de uma sociedade que gradualmente se pautava pelo individualismo concebido pelos sistemas de pensamento moderno, notadamente o humanismo e o iluminismo, culminando na pluralidade de visões característica dos séculos XIX e XX. Desenvolvido e tratado de modo insuperável por Goethe, o mito fáustico foi posteriormente retomado por diversos autores, os quais lhe deram uma feição e uma forma diferentes daquelas do drama goethiano. Entre esses autores está Fernando Pessoa. Seu Fausto, no entanto, pode ser visto como um desenvolvimento bastante peculiar da tradição fáustica. Nele, afasta-se o sujeito do domínio da ação para o domínio do pensamento, do isolamento e do desespero ante a impossibilidade de compreensão da realidade da Vida. Como introdução ao tema e para melhor entender alguns aspectos da tragédia pessoana, convém desenvolver uma breve trajetória da tradição fáustica, identificando seus principais expoentes e suas principais características, culminando em Goethe, para então comentar sua recepção no ambiente literário português e, por fim, em Fernando Pessoa. Traça-se então um paralelo de divergências entre os dramas goethiano e pessoano, identificando as principais características da tragédia subjetiva idealizada pelo poeta português.

\section{O mito fáustico e seu desenvolvimento na literatura}

O mito fáustico tem origem em um personagem real, Johann Faustus ${ }^{2}$, um homem que viveu provavelmente entre os anos de 1480 e 1540 em diversas regiões da Alemanha. Sua existência é atestada por documentos emitidos por autoridades administrativas de cidades pelas quais provavelmente passou ${ }^{3}$ e por meio de relatos em cartas e conversas, em especial as de Johannes Trithemius, Lutero e Melanchton. Fausto é caracterizado por uns como charlatão, nigromante, sodomita ou andarilho; por outros, como estudioso de magia, conhecedor de muitas artes e "doutor". Uma constante nos relatos sobre o homem Fausto é sua possível ligação com o diabo, manifesta por supostas demonstrações de magia que operava. Melanchton relata uma dessas demonstrações, que teria ocorrido em Veneza: "Assim, o diabo elevou-o e depois deixou-o cair, de tal maneira que ficou inanimado no chão e quase morto" (Rita Iriarte in BARRENTO, 1984, p. 22).

\footnotetext{
2 O nome de Fausto varia conforme a fonte, ocorrendo também como Johann Faustus, Georg Sabellicus, Johann Fausten, Jorg Faustus, Georgius Faustus, entre outros.

3 Cita-se, como exemplo, um recibo de 1520 a "Doctor Faustus Philosopho" escrito pelo bispo Georg III em relação a serviços de astrologia prestados a ele (MASON, 1989, p. 26).
} 
A época na qual a crítica situa o nascimento e a morte de Fausto é um período de intensas transformações políticas, intelectuais e religiosas, destacando-se a Reforma Protestante. Ao mesmo tempo, alastrava-se pela Alemanha uma revolta camponesa contra a opressão e o autoritarismo dos donos do poder, estes ainda remanescentes de um sistema feudal, e duramente reprimida no episódio do massacre de camponeses em Frankenhausen em 1525. Em 1555, a descentralização religiosa se tornou completa com a Paz de Augsburg, segundo a qual cada príncipe poderia decidir a religião praticada em seu principado. O dono das terras, portanto, teria, além dos controles político, econômico e social, o controle religioso dos habitantes de suas terras. Consequentemente, o príncipe também controlava o aspecto cultural de sua região (SILVA in BARRENTO, 1984, p. 37-39). Segundo Gerald Strauss (1989, p. 29, tradução e destaques nossos),

Tais princípios eram: primeiro, ordem, então razão, depois condições de obediência, lógicas de uniformidade e ortodoxia e a autoridade da palavra escrita; finalmente, subjacente a todos esses, uma fé inquestionada na existência objetiva da verdade acompanhada da convicção de que tal verdade pode ser conhecida e formulada como leis de fé e de conduta.

A crença na autoridade da palavra escrita é um dos fatores que influenciaram a popularidade do livro anônimo editado por Johann Spies em 1587, a primeira manifestação literária de Fausto.

O ambiente intelectual do período observou a redescoberta de escritos gregos e latinos, que passaram a ser estudados pelas classes eclesiásticas europeias, notadamente as italianas, espalhando-se para o restante da Europa durante os dois séculos seguintes. Nesse momento, os autores compunham suas obras com base na emulatio dos autores antigos, inserindo personagens mitológicas no âmbito de textos com matiz cristão (HELLER, 1982). É nesse momento que a figura do diabo se estabelecerá como um ente individuado capaz de agir por si próprio e seguindo sua própria vontade (SILVA in BARRENTO, 1984). O diabo passa então a ter uma presença "concreta" no meio social, sendo utilizado como ameaça para infrações à lei divina.

É nesse contexto que as supostas manifestações de magia ou habilidades sobrehumanas de Fausto são associadas ao diabólico. A superstição em relação ao magocharlatão desperta a atenção de Melanchton, que atribui a morte de Fausto em uma explosão alquímica na cidade de Staufen ao trabalho do diabo. Segundo Ian Watt, os reformadores, incluindo Melanchton, foram os primeiros que ligaram Fausto ao diabo, porém o pacto, motivo central na tradição fáustica, foi mencionado pela primeira vez somente no Faustbuch de 1587 (WATT, 1996). 
O editor Johann Spies publica em Frankfurt um livro popular (Volksbuch) chamado Historia von D. Johann Fausten, em título abreviado, em 1587, contendo a primeira versão literária impressa da lenda de Fausto. O volume encontrou grande apreciação por parte do público, tendo sido reeditado diversas vezes ${ }^{4}$ e dando ensejo ao desenvolvimento inicial da temática fáustica. Fausto é apresentado como o filho de um camponês das cercanias de Weimar que fora enviado a Wittenberg e ali se tornou Doctor Theologiae (Historia, 2011). No sexto capítulo, há a introdução do pacto com o diabo, pelo qual Fausto promete sua alma em troca de vinte e quatro anos de serviços prestados pelo "servente do príncipe infernal do oriente" (Historia, 2011, p. 15). Inicia-se um relato sobre as aventuras do Doutor Fausto, passando por viagens, a apresentação de seu fâmulo Wagner, experiências físicas, aprendizado sistemático do mundo, uma visita ao inferno, a união com Helena, até a morte do protagonista.

O Faustbuch pode ser lido como um livro de educação religiosa tendo em vista o sentido pedagógico que os Volksbücher então possuíam. Por pactuar com o diabo para a conquista de prazeres terrenos e por pretender acesso amplo ao conhecimento ${ }^{5}$, fato este proibido segundo a doutrina religiosa da época, Fausto incorre em crime contra a lei de Deus. Destarte, merece a punição, ou seja, a morte, o que ocorre ao final do livro junto a admoestações aos leitores a não se desviarem do caminho da fé (Historia, 2011).

O livro de Spies concentra três traços principais do posterior desenvolvimento da tradição fáustica: a cultura popular; o protestantismo e suas ideias, relacionando Fausto à figura do diabo e ao destino da alma do pactário; e ideias renascentistas e humanistas, em que a retomada da cultura greco-latina aparece na figura de Helena e nas menções a personagens da mitologia (SILVA in BARRENTO, 1984, p. 35; Benz in Historia, 2011, p. 163).

Literatura em parte sapiencial, transmite a doutrina protestante para aplacar a curiosidade da sociedade de então sobre as ditas "ciências secretas". O livro impresso, aliado à crença na palavra escrita proposta pelos luteranos e ao pecado da curiositas que Fausto despertava no meio popular, deram amplitude à sua lenda (MOURA in História do Doutor Johann Fausto, 2019).

Essa amplitude abrangeu a Europa. São encontradas traduções desse livro para o holandês e o francês já nos primeiros anos após sua publicação. No entanto, a mais importante tradução do Faustbuch foi a inglesa, publicada em 1592 como The Historie of

4 Dabezies menciona que no ano de 1599 já havia vinte e duas edições do texto (DABEZIES, 1972).

5 Segundo Georg Gödelmann (1559? - 1611), um demonólogo, “O desejo excessivo de conhecer o futuro e coisas secretas (pelas quais nossos primeiros pais também se desencaminharam) é o principal motivo de os que praticam as artes negras se ligarem ao Diabo" (Gerald Strauss in BORNER, 1989, p. 34). 
the Damnable Life, and deserved Death of Doctor John Faustus (A história da vida condenada, e da morte merecida do Doutor John Faustus) (WATT, 1996). Segundo Ian Watt, essa tradução do Faustbuch é adaptada e livre, divergindo em alguns pontos da narrativa original. Foi, no entanto, a principal fonte para o dramaturgo inglês Christopher Marlowe compor a primeira peça teatral dedicada a Fausto: The Tragicall History of the Life and Death of Doctor Faustus (A trágica história do Doutor Fausto). Segundo André Dabezies, a peça foi escrita provavelmente entre 1589 e 1592 e publicada em texto pela primeira vez em 1604, acrescida de interpolações e modificações. Tais modificações surgem em uma segunda edição, em 1616, que apresenta um texto mais longo sem precisar a autoria de tais mudanças (DABEZIES, 1972).

A peça inglesa surge em um período de movimentações revolucionárias da sociedade burguesa do século XVI inglês. Com os escritos de John Donne, o questionamento acerca de todos os temas possíveis toma a forma de um espírito ativo, uma atitude intelectual que encontra em Fausto sua representação magna. Fausto não é mais o mago praticante de magia negra que erra de cidade em cidade realizando demonstrações de suas supostas habilidades. Com Marlowe, Fausto tornase o alquimista, o estudante sério de filosofia e de outras áreas do saber, que contesta a doutrina estabelecida e busca o conhecimento do universo sem a subserviência ao pensamento religioso (BARRENTO, 1984). A revolta contra o pensamento doutrinário e o estudo solitário visando ao engrandecimento intelectual são sintomas do crescente individualismo nascente no século XVI.

Caracterizada como tragédia, no entanto, a vida de Fausto ainda está incluída em uma subestrutura de cunho cristão: ao final da tragédia, Fausto clama por perdão divino ante a proximidade do final do prazo pactuado, porém os diabos o recolhem e o levam à danação infernal. O Coro que fecha o desenlace trágico traz, da mesma maneira que o Faustbuch, uma admoestação aos espectadores: "Que seu fim terrível [hellish] exorte os sábios / A apenas pensar no que é proibido, / Pois seu mistério incita o infiel / A tentar mais do que permite o céu" (MARLOWE, 2018, p. 211). A busca da sabedoria universal, dos segredos do mundo, por meio das ciências ocultas ainda é objeto de danação da alma. A importância da peça de Marlowe, no entanto, não reside no desenlace, mas sim na caracterização do personagem Fausto, que diverge do Faustbuch de 1587. O mito de Fausto se torna um símbolo da resistência à opressão ao desejo de conhecimento e ao prazer.

O Tragicall History de Marlowe inseriu Fausto no repertório do teatro; ou, mais amplamente, segundo lan Watt, foi o texto que de fato instaurou na literatura o mito fáustico (WATT, 1996). Após esse texto, houve diversas representações em variadas obras 
até seu ponto culminante com Goethe. Diversas narrativas ficcionais relatando a história de Fausto surgem nos séculos XVI a XVIII. Para citar brevemente dois exemplos desses textos, há a Saga de Christopher Wagner, o fâmulo (1593) e as diversas peças de teatro de marionetes (Puppenspiel), que seguem em maior ou menor grau o mito de Fausto atualizado para a época em que foram representadas (MAHAL in Doktor, 2007). Nesses textos, Fausto é ainda condenado à danação e não tem possibilidade de salvação.

Segundo Eloá Heise, o ponto de virada em relação à danação de Fausto se dá com Lessing, que se baseia em ideais iluministas (HEISE in VOLOBUEF, 2011). Lessing publica em 1759, na revista 17. Literaturbrief, um esboço de uma peça com temática fáustica incorporando tais visões (HENNING in BORNER, 1989). A diferença em relação aos textos anteriores é que Fausto não mais será condenado à danação eterna por ter pretendido conhecer o funcionamento da máquina do mundo. É precisamente por isso, ou seja, pela busca incessante da verdade, que merecerá a redenção. A possibilidade de considerar a busca por conhecimento como não passível de punição será uma das fontes para o Fausto goethiano, cujo personagem, ao final de seu caminho pelo "grande mundo", encontrará a redenção.

É com Johann Wolfgang von Goethe que o mito fáustico encontrará o ápice de seu desenvolvimento. Com longa gênese abrangendo um período de sessenta anos, Goethe partiu das impressões que tivera com as peças de teatro de marionetes ainda em sua infância para desenvolver sua obra máxima e repensando a temática fáustica em diversos aspectos. A obra possui, em sua primeira parte, a que mais de perto interessa ao presente estudo, dois temas principais: a "tragédia do erudito", a busca incessante por um saber que não se depreende só de livros, mas também da experiência, inovando a temática do pacto com o diabo; e a "tragédia de Gretchen", inspirada pelo caso de Susanna Margareta Brandt, que cometeu um infanticídio em 1771 (BOYLE, 1991) e que foi levada à ruína devido ao assassinato (MAZZARI in GOETHE, 2007).

Fausto agora é um doutor que estudou a maior parte das áreas formais do conhecimento, porém que não encontra satisfação pornão sercapaz de responderàs ânsias que o incomodam. Fausto deseja conhecer os segredos da natureza e do funcionamento do mundo, conhecimento inacessível ao "sábio de gabinete", personificado em Wagner, seu fâmulo. $\mathrm{O}$ aparecimento da figura do diabo, Mefistófeles, abrirá a possibilidade para Fausto alcançar esse conhecimento mediante o rompimento com o "pequeno mundo", o mundo subjetivo, para o "grande mundo", a experiência da ação. Para tanto, Fausto pactua com Mefistófeles o acesso a essa experiência. Goethe inova o motivo do pacto: trata-se, nos moldes do Livro de Jó, dos termos de uma aposta, que será perdida se Mefistófeles apresentar a Fausto, espírito inquieto, algo que o satisfaça. Ela inclui, além do acesso ao 
conhecimento, o acesso ao prazer, que será personificado em Gretchen, na primeira parte, e em Helena, na segunda parte da tragédia (BARRENTO, 1984).

A obra de Goethe, notadamente a primeira parte, publicada em 1808, teve uma ampla recepção nos demais países europeus, notadamente na França, onde surgem traduções em prosa e em verso já nos anos seguintes à publicação do original, tal como a de Gérard de Nerval, publicada em 1827 e muito apreciada por Goethe. Além de versões literárias, a obra foi adaptada para teatro e ópera. No âmbito da ópera, menciona-se em especial a versão de Charles Gounod, encenada pela primeira vez em 1859 em Paris. Baseada no libreto de Michel Carré e Jules Barbier, Faust et Marguerite, Gounod enfatiza a "tragédia de Gretchen", narrando desde a cena do quarto de trabalho até a Noite de Valpúrgis, momento em que, na ópera, Fausto chora a morte de Marguerite. Apesar do parco sucesso inicial, a peça ganhou fama, sendo encenada em diversas casas de ópera da França e chegando aos Estados Unidos. A montagem dessa ópera em Portugal marca uma das primeiras manifestações de interesse pelo mito fáustico nas letras portuguesas.

\section{Fausto nas letras portuguesas}

Em Portugal, no início do século XIX, o mito fáustico não teve recepção muito ampla e se limitou a poucas menções por alguns autores e em poemas esporádicos publicados em periódicos. É possível caracterizar três meios pelos quais o mito fáustico foi recepcionado em Portugal.

O primeiro é a menção ao Fausto de Goethe por Almeida Garrett em dois pontos de sua obra Viagens na minha terra. No capítulo XXVIII, Almeida Garrett, de maneira inédita em Portugal, traduz um fragmento da dedicatória do poema goethiano ao comentar a visão de uma paisagem do Além-Tejo (GARRETT, 1846).

Somente em 1867 será publicada uma tradução integral, em versos, da primeira parte da tragédia de Goethe pela mão de Agostinho d'Ornellas, diplomata português na Alemanha, reconhecida desde então pela crítica como uma tradução fiel e poética, em que pesem censuras a aspectos pontuais (BARRENTO, 2006). Em 1873, d'Ornellas publica a tradução integral da segunda parte da tragédia, perfazendo, dessa maneira, a primeira tradução integral da obra de Goethe em português.

Em 1872, após ter sido impressa no periódico $A$ Folha, Antônio Feliciano de Castilho publica em livro sua tradução da primeira parte da tragédia de Goethe. Como afirmado pelo próprio tradutor, sua versão é baseada na tradução feita por um amigo alemão, na tradução feita por seu irmão, na tradução de d'Ornellas e em outras quatro traduções francesas em prosa (CASTILHO, 1964). Essa tradução, bastante controversa, suscitou uma 
- | A tradição fáustica e a tragédia subjetiva no Fausto de Fernando Pessoa

polêmica em torno dos métodos de tradução que foi chamada de a "Questão Fáustica", associada à já em andamento "Questão Coimbrã". A título de exemplo, Joaquim de Vasconcelos, erudito e conhecedor do idioma alemão, publica um volume intitulado $O$ Fausto de Castilho, julgado pelo elogio-mútuo, em 1873, no qual aborda questões específicas da tradução de Castilho. Segundo Maria Manuela Gouveia Delille, a "Questão Fáustica" marca o início da germanística em Portugal (DELILLE in BARRENTO, 1984).

Questões polêmicas à parte, o mito fáustico passou a despertar a atenção de autores portugueses, que compuseram poemas e dramas baseados na figura goethiana. Assim, Gomes Leal publica na década de 1860 um fragmento de temática fáustica intitulado $A$ tragédia do mal, colocando em diálogo as figuras de Fausto e Mefistófeles. A temática do desespero já aparece configurada no poema e será cara ao Fausto de Fernando Pessoa. Teófilo Braga, por sua vez, publica uma série de três poemas fáusticos, Vertigem do infinito (1869), Vigílias do Fausto (1895) e Psicose do Fausto (1901), em que Fausto é caracterizado como o homem que usa a razão para se sobrepor às "fantasmagorias" criadas pela "psicose", identificadas pelo autor como o problema de Portugal no final do século XIX (SCHEIDL, 1987). Em 1895, Eugénio de Castro publica Sagramor, apresentando um homem fáustico "desiludido" em relação a todas as possibilidades oferecidas pelo mundo, desde o amor até a ciência, revelando traços de desesperança (DELILLE in BARROSO, 1984).

O segundo meio da introdução do mito fáustico em Portugal é o grande sucesso popular da ópera de Charles Gounod. Ela estreou em Lisboa em dezembro de 1865 e foi reiteradamente reapresentada devido ao sucesso de público (LASCH, 2006), levando um jornalista da época a afirmar que "Fausto se tornara verdadeira mania portuguesa" (ROSENTHAL, 1990, p. 39). O sucesso da peça chamou a atenção de Eça de Queiroz que, em um artigo intitulado "Mefistófeles", centraliza a obra dramática de Gounod na figura de Mefistófeles ("Aquela obra é uma simples aventura do antigo Diabo"), criticando a apresentação de Fausto, não como o sábio da obra de Goethe, mas como "um daqueles ambiciosos grotescos" (QUEIROZ, s/d, vol. 2, p. 652) pedindo ao diabo a realização de uma "pequena coisa desprezível" (QUEIROZ, s/d, vol. 2, p. 655).

O terceiro meio é outro trecho do capítulo XXXIX de Viagens na minha terra, de Almeida Garrett. Em passagem por Santarém, o narrador contempla o local em que se encontra a figura lendária de S. Frei Gil de Santarém: "Algures lhe chamei já o nosso Doutor Fausto; e é com effeito. Não lhe falta senão o seu Goethe" (GARRETT, 1846, vol. 2, p. 137). É com Frei Gil de Santarém, uma figura mítico-lendária que vivera na época da Primeira Renascença, envolvido em disputas de poder de D. Afonso II sobre o testamento de D. Afonso I, que os autores portugueses, notadamente Almeida Garrett, Eça de Queiroz e Teófilo Braga, tentarão dar forma a um "Fausto português". Frei Gil, segundo Garrett (1846, 
vol. 2, p. 137-138), possuía um grande anseio pelo saber, por conhecer o funcionamento da natureza; desejava riqueza, prazer e poder, sendo esses os principais motivos para se aliar ao diabo. Figura não incontroversa, Frei Gil se afasta da lenda fáustica justamente na aproximação ao diabo: nesse caso, não há uma busca por parte de Frei Gil; o diabo é que se lhe apresenta, oferecendo a realização de seus desejos. Trata-se, portanto, não da história de revolta, mas sim de tentação (SCHEIDL, 1987). Teófilo Braga, partindo desses pressupostos, comporá um drama, Frei Gil de Santarém, no qual pretenderá desenvolver a personagem sob três óticas: a histórica, a fáustica e a programática (ou seja, seguindo o desenvolvimento das teses sociais em voga no século XIX) (SCHEIDL, 1987).

A lenda de Frei Gil de Santarém também foi projeto de Eça de Queiroz. Em seu espólio, foram encontrados um "Plano da Obra" e os oito primeiros capítulos de um romance planejado pelo autor. Nesse plano, pode-se ler o seguinte percurso para Frei Gil: amor pelo desconhecido e ânsia de abranger todo o conhecimento possível do mundo, estudo das artes negras, assinatura do pacto, ambição de poder, desejo de conhecer mistérios, viagens maravilhosas, renegação da vida, vida em monastério, tentação pelo diabo, rezas à Virgem Maria, arrependimento, quebra do pacto e, por fim, vida santificada (QUEIROZ, s/d, vol. 2). Eça de Queiroz dá a redenção a seu personagem, mostrando que $\mathrm{o}$ arrependimento verdadeiro remite os pecados.

\section{O Fausto de Fernando Pessoa}

Fernando Pessoa deixou em seu espólio diversos planos para obras que intencionava compor. Entre elas, o personagem Frei Gil de Santarém é mencionado em três ocasiões (PESSOA, 1988). Até o presente momento, considerando o contínuo andamento da publicação do imenso espólio de Fernando Pessoa, obra alguma com esse título foi descoberta. O poeta, no entanto, tornou ao mito fáustico, escrevendo continuamente a obra (inacabada) com que se ocupou desde 1908 até perto do fim de sua vida em 1934 (GUSMÃO in BARRENTO, 1984).

O Fausto de Fernando Pessoa não chegou a ser publicado, nem mesmo the foi dada uma configuração final. As edições modernas são recolhas de fragmentos que o poeta escrevera, identificadas por rubricas como "F." ou "Fausto", reunidas e ordenadas de diferentes maneiras por estudiosos da obra pessoana. Teresa Sobral Cunha, em 1988, após minucioso trabalho de leitura e análise dos fragmentos constantes do espólio, deuIhes uma ordenação com base nos planos de obras deixados pelo poeta ${ }^{6}$.

6 Uma nova edição, esta crítica, foi publicada em 2018 organizada por Carlos Pitella. Este trabalho segue a edição de Sobral Cunha. 
Visto de uma maneira geral, os 214 fragmentos poéticos que compõem o Fausto de Fernando Pessoa formam essencialmente um monólogo lírico, interiorizado, no qual o protagonista pretende "encenar o sentido" (LOURENÇO in PESSOA, 1988, p. XV), dando vazão a elucubrações acerca de seu interior, primordialmente dramático, tendo em vista o desfecho trágico pretendido (a morte de Fausto). Pontuadas aqui e ali estão presentes poucas cenas de diálogo: com o Velho, que possui o "filtro" para a solução do drama da consciência; com Maria, "a beleza real" (PESSOA, 1988, p. 193); a "Cena na Taberna", início de um movimento de revolta no $4^{\circ}$ Ato; entre outros.

A levar em consideração os planos da obra, o tema geral é o "mistério do mundo", por sua vez relacionado ao tema central da "Inteligência" (PESSOA, 1988, p. 190), ou seja, o pensamento7, a consciência do "mistério" do mundo, levando à solidão profunda e ao desespero, e o horror da morte, presente na maioria dos fragmentos ( $L A S C H, 2006$ ). Fernando Pessoa pensou o drama dividido em cinco atos e entreatos que teriam caráter de comentário ao ato precedente, nos moldes da tragédia grega clássica. No $1^{0}$ Ato é representada a luta "entre a Inteligência e a Vida", entre o pensamento acerca da vida e da realidade, considerada por seu Fausto como inapreensível visto que filtrada pelo pensamento. No $2^{\circ}$ Ato é representada a luta da "Inteligência para dirigir a Vida", ou seja, o domínio da Vida através do pensamento. No $3^{\circ}$ Ato é representada a luta da "Inteligência para se adaptar à Vida", luta essa, como as anteriores, perdida, pois a Inteligência não é capaz de se adaptar à realidade que a Vida apresenta ("Há entre mim e o real um véu / À própria concepção impenetrável"; PESSOA, 1988, p. 87). Nesse ato, Fausto entra em contato com o amor real, não idealizado, personificado em Maria, que ama Fausto concretamente, motivo pelo qual ele não consegue a corresponder, pois sua concepção de amor é baseada na ideia que Fausto tem dele e não em sua manifestação concreta, tangível. No $4^{\circ}$ Ato é representada a reação da Vida à tentativa de sobreposição da Inteligência a ela, levando Fausto da rebeldia presente na Cena na Taberna ao isolamento completo, perdendo o sentido que a vida poderia ter à revelia do pensamento. No $5^{\circ}$ Ato a Inteligência é derrotada pela Vida, representada, após um momento de delírio, pela Morte, que possibilitará a anulação da existência e o suposto fim do pensamento.

O espaço dramático no Fausto de Pessoa é um "abismo" existencial, um labirinto no qual a possibilidade de se perder é certa e de onde não se sai, permanecendo o sujeito em completa solidão. O tempo tampouco tem contornos precisos. Trata-se de um tempo

7 Conforme atesta Benedito Nunes (2009, p. 207), para Fernando Pessoa, o pensamento, uma forma de afastamento das sensações do mundo, é "o primado da consciência reflexiva". O sentir é sempre entremeado pela reflexão acerca daquilo que se imaginou sentir em determinado momento. Sendo reflexão, não é mais sensação, tornando, para Pessoa, impossível de fato sentir . 
que existe no pensamento, ou seja, o tempo sem a cronologia da existência concreta. Não há claramente um passado ou um futuro; há um tempo presente no qual as reflexões de Fausto ocorrem. Esse presente, no entanto, é "uma espécie de suspensão no tempo", um "presente vazio" (GUSMÃO in BARRENTO, 1984, p. 162). Dadas essas condições, não há ação propriamente dita, no sentido do drama tradicional, na tragédia subjetiva pessoana. Trata-se de um monólogo entoado por uma voz que fala sobre sua própria existência, uma fala - ou lamento - cheia de contradições, que reflete sobre o significado íntimo e obscuro das coisas e que ora busca a compreensão, sabendo-a impossível, ora busca a solução de toda forma de pensamento na morte. Como exemplo disso, no $4^{\circ}$ Ato Fausto clama seus companheiros de bebida a abraçar o concreto, sentir a vida por meio do vinho, para, logo em seguida, retomar a consciência de que viver o concreto não é possível, restando somente a última possibilidade que se abre ao sujeito que conhece o mundo: a morte como saída do inferno que é pensar ( $5^{\circ}$ Ato).

O que o Fausto pessoano busca é a compreensão do "mistério" que a vida não tem a capacidade de revelar. Durante toda a obra, Fausto buscará, por meio da reflexão, compreender o sentido oculto que subjaz a toda a vida, sensações e pensamentos íntimos que compõem a integralidade de seus anseios. Porém, ao refletir sobre essa busca, Fausto descobre que isso é impossível de ser descoberto no plano da existência concreta, e até mesmo no plano do pensamento. Paradoxalmente, é na experiência real que as sensações, fonte da sabedoria pretendida por Fausto, podem ser encontradas; todavia, essas sensações reais são entremeadas pelo pensamento, pela reflexão acerca delas, tornando-as impossíveis de serem compreendidas:

\author{
A essência de mistério o seu horror \\ Está em não só em nada compreender \\ Mas em não saber porque nada se compreende. (PESSOA, 1988, p. 135).
}

O mistério não pode ser acessado pelo pensamento, razão pela qual se transforma em horror, palavra presente em toda a tragédia. Fausto encontrará na morte, ou melhor, na experiência da morte, a única experiência possível, a possibilidade de talvez contemplar a Verdade, já que a morte, "a incompreendida / Revelação do mais que incompreendido" (PESSOA, 1988, p. 174), é inevitável. Essa inevitabilidade se configura como a única certeza de Fausto, o que lhe amplia a sensação de horror:

\title{
Dois horrores
}

Me esmagam, cada um dos quais parece

O maior dos horrores que há maiores: 


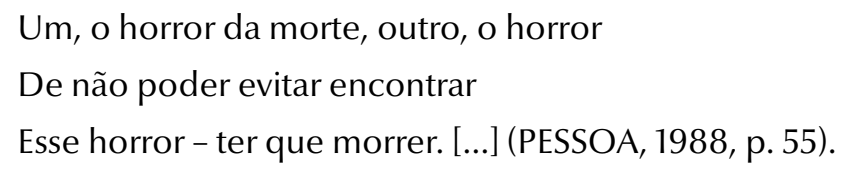

Como no Fausto goethiano, a busca pelo saber totalizante, uma característica comum na tradição fáustica, não acontece no Fausto pessoano. Ele está sempre um passo aquém da obtenção do saber através da experiência, razão pela qual, em Goethe, Mefistófeles insta Fausto a sair de seu quarto de estudos para experimentar o pequeno e o grande mundo. Em Pessoa, o desejo de saber é unificante, totalizador, concentrado em uma única compreensão de todo o conteúdo presente no intelecto ("[...] aspiro: / O pensamento abrangedor de tudo / Numa compreensão única e funda"; PESSOA, 1988, p. 52). Não alcançando esse intento, Fausto tem consciência, porém, de que o mero questionar acerca da realidade e da existência do "mistério" o torna superior aos outros homens: "Já irmanar não posso o sentimento / Com o sentimento doutros, misantropo / inevitavelmente e em minha essência" (PESSOA, 1988, p. 13).

A retração à experiência também se desenvolve em torno do amor. O Fausto pessoano não tem a capacidade de amar plenamente visto que sua concepção do amor é idealizada. Pretende acessar o prazer por meio de orgias e bebida (por exemplo, a Cena na Taberna; PESSOA, 1988), porém é incapaz de apreender qualquer sentido e passa a questionar o amor por ele não conseguir acessar qualquer tipo de espiritualidade. No terceiro ato, no diálogo entre Fausto e Maria (PESSOA, 1988), ela é caracterizada como similar à Gretchen goethiana na intensidade do amor que devota a Fausto: "Amo como o amor ama. / Não sei razão pra amar-te mais que amar-te" (PESSOA, 1988, p. 99). A hesitação de Fausto é de ordem intelectual: "Compreendo-te tanto que não sinto" (PESSOA, 1988, p. 101). Segundo a rubrica que encima o diálogo, "sua incapacidade não só de compreender o amor, como até de o sentir ou, talvez melhor, de se sentir sentindo-o, que esse abismo que existe entre ele e o amor começa por ser um abismo que existe entre ele e ele próprio" (PESSOA, 1988, p. 99), Fausto reluta na entrega amorosa, especialmente a corporal ${ }^{8}$, não por qualquer característica de Maria, mas por si mesmo, por se perder no "abismo" que separa seu eu-concreto de seu eu-pensamento, e somente este agindo sobre o amor. O Fausto goethiano tem a capacidade de amar e de sentir amor; o Fausto pessoano, condenando o amor como "vil e baixa porca animalidade do animal" (SCHEIDL, 1987, p. 123) tem a "maldição" de ser incapaz de compreender o amor (SCHEIDL, 1987, p. 133).

8 "O pensamento impede-me e confrange-me / Do terror de ter perto e comungar / Em sensação ou ser com outro corpo" (PESSOA, 1988, p. 97); "Pudesse eu amar sem que existisses / E possuir-te sem que ali estivesses!" (PESSOA, 1988, p. 105). 
Por fim, o ponto de contraste mais acentuado dos dramas pessoano e goethiano reside na apreensão do momento que se eterniza, motivo da resolução do pacto no Fausto do poeta de Weimar. Fausto perderá a aposta com Mefistófeles se este apresentar àquele um momento que possa ser gozado como eternidade, momento no qual Fausto se tornará realizado ao contemplá-lo. Esse momento, em Goethe, ocorre no final da segunda parte da tragédia, no qual Fausto, na presciência do resultado de seus empreendimentos, contempla sua obra de colonização e admite a condição de eternidade do momento, perdendo a aposta (vv. 11.581-11.586). Em Fernando Pessoa, Fausto busca o ser abstrato, a resolução última do mistério: ao final, contemplando a Verdade e o Horror do Mistério, Fausto deparara-se com o ser supremo, eterno, cuja existência é igualmente eterna (SCHEIDL, 1987). O Fausto pessoano busca atingir esse objetivo com a reflexão, com o pensamento, prescindindo portanto de qualquer aposta ou pacto, ou até mesmo da figura do diabo, que não será capaz de fazê-lo compreender o mistério, por natureza incompreensível.

Essa incompreensão causa angústia ao Fausto pessoano por se tratar de uma limitação ao acesso ao conhecimento. Na tradição fáustica de modo geral, e no Fausto de Goethe em particular, o que caracteriza o fáustico é, justamente, a transgressão dos limites do conhecimento humano e a busca, através de um ente metafísico, no caso o diabo, de uma sabedoria que é vedada ao homem comum. Em Pessoa, esse conhecimento não é acessível nem aos deuses: "Deus a si próprio não se compreende. / Sua origem é mais divina que ele" (PESSOA, 1988, p. 71). A compreensão, portanto, é inatingível, perpetuando o mistério do mundo para dimensões infinitas, não passíveis de resolução mesmo se se igualando à divindade.

\section{Considerações finais}

Fernando Pessoa buscou levar o drama fáustico da ação para o terreno do pensamento próximo ao puro metafísico. Essa intenção é um afastamento da tradição fáustica, na qual a busca por conhecimento e pela exploração das possibilidades sensuais é dada por meio da experiência; em última análise, da ação. Fernando Pessoa denominou o conjunto de fragmentos que compõem seu drama como uma "tragédia subjectiva". Segundo Benedito Nunes (2009, p. 210), em Fernando Pessoa a "subjetividade transformase numa sucessão de reflexos". Tal é o matiz do drama pessoano: trata-se de um monólogo lírico no qual o protagonista tece reflexões sobre a possibilidade de compreensão da Vida e do mistério do mundo, revelado somente no momento da morte que eterniza a existência. $\mathrm{O}$ afastamento em relação à tradição fáustica é percebido nos trechos comentados, ou seja, a concretização carnal do amor, a apreensão do momento eterno 
- | A tradição fáustica e a tragédia subjetiva no Fausto de Fernando Pessoa

pelo Fausto de Goethe em contraste com o de Pessoa, e o objetivo da busca incessante por conhecimento.

Em Pessoa, mistério, desespero e horror se entremeiam em uma eterna angústia, na qual o pensamento de Fausto buscará o acesso ao conhecimento dos mecanismos do mundo. Sua intenção será sempre falha, tendo em vista que Fausto não é capaz de apreender ou compreender o conhecimento que jaz além-Vida, inacessível até mesmo aos deuses. No início com horror à experiência da morte, Fausto, ao final, atingindo um niilismo absoluto no qual a vida não possui e nem pode possuir qualquer sentido, encontrará na morte e na cessação da existência concreta a contemplação da Verdade e o esclarecimento do Mistério, ainda que essa experiência seja a origem de seu horror. O desenlace não está presente no drama subjetivo conforme organizado atualmente, deixando abertas as possibilidades de interpretação da tragédia fáustica pessoana.

\section{Referências}

BARRENTO, J. Fausto na literatura europeia. Lisboa: Apaginastantas, 1984.

BARRENTO, J. Fausto: as vozes do texto. In: BARRENTO, J. O arco da palavra. São Paulo: Escrituras, 2006.

BENZ, R. Nachwort. In: BENZ, R. Historia von D. Johann Fausten. Stuttgart: Reclam, 2001.

BORNER, P. et al. Faust through Four Centuries: Retrospect and Analysis. Tübigen: Max Niemeyer Verlag, 1989.

BOYLE, N. Goethe: The Poet and the Age. Volume I: The Poetry of Desire (1749-1790). Oxford: Clarendon Press, 1991.

CASTILHO, A. F. de. Advertência do tradutor. In: GOETHE, J. W. von. Fausto. Tradução Antônio Feliciano de Castilho e prefácio de Otto Maria Carpeaux. São Paulo: W. M. Jackson Editores, 1964.

DABEZIES, A. Le mythe de Faust. Paris: Armand Colin, 1972.

Doktor Johannes Faust: Puppenspiel. Stuttgart: Reclam, 2007. 
GARRETT, A. Viagens na minha terra. v. 2. Lisboa: Typographia da Gazeta dos Tribunais, 1846.

GOETHE, J. W. von. Fausto: uma tragédia. Tradução Jenny Klabin Segal. Introdução e notas de Marcus Vinicius Mazzari. 2 vols. São Paulo: Editora 34, 2007.

História do Doutor Johann Fausto. Tradução, estudo e comentários de Magali Moura. São Paulo: Filocalia, 2019.

HEISE, E. Mito e Magia no Fausto de Goethe. In: VOLOBUEF, K. (org.). Mito e magia. São Paulo: Unesp, 2011.

HELLER, A. O homem do Renascimento. Tradução Conceição Jardim e Eduardo Nogueira. Lisboa: Presença, 1982.

Historia von D. Johann Fausten. Stuttgart: Reclam, 2001.

LASCH, M. Pessoas Faust. Fragmente einer subjektiven Tragödie. Freiburg: Rombach, 2006.

MARLOWE, C. A trágica história do Doutor Fausto. Tradução Caetano Galindo. São Paulo: Ateliê Editorial, 2018.

MASON, J. O Dr. Fausto e seu pacto com o demônio: o Fausto histórico, o Fausto lendário e o Fausto literário. Rio de Janeiro: Objetiva, 1989.

MAZZARI, M. V. Goethe e a história do Doutor Fausto: do teatro de marionetes à literatura universal. In: GOETHE, J. W. von. Fausto: uma tragédia. Tradução Jenny Klabin Segall. Introdução e notas de Marcus Vinicius Mazzari. v. 1. São Paulo: Editora 34, 2007.

NUNES, B. Os outros de Fernando Pessoa. In: NUNES, B. O dorso do tigre. 3. ed. São Paulo: Editora 34, 2009. p. 205-225.

PESSOA, F. Fausto: tragédia subjectiva. Texto estabelecido por Teresa Sobral Cunha e prefácio de Eduardo Lourenço. Lisboa: Presença, 1988. 
- | A tradição fáustica e a tragédia subjetiva no Fausto de Fernando Pessoa

QUEIROZ, E. de. Mefistófeles. In: QUEIROZ, E. de. Obras de Eça de Queiroz. v. 1. Porto: Lello \& Irmão, s/d.

QUEIROZ, E de. São Frei Gil. In: QUEIROZ, E. de. Obras de Eça de Queiroz. v. 2. Porto: Lello \& Irmão, s/d.

ROSENTHAL, E. T. Perfis e sombras: estudos de literatura alemã. São Paulo: EPU, 1990.

SCHEIDL, L. Fausto na literatura portuguesa e alemã. Coimbra: Instituto Nacional de Investigação Científica, 1987.

WATT, I. Myths of modern individualism: Faust, Don Quixote, Don Juan, Robinson Crusoe. Cambridge: Cambridge University Press, 1996.

COMO CITAR ESTE ARTIGO: SANTOS, Rafael Rocca dos. A tradição Fáustica e a tragédia subjetiva no Fausto de Fernando Pessoa. Revista do GEL, v. 17, n. 2, p. 214-229, 2020. Disponível em: https://revistadogel.gel.org.br/

DOI: http://dx.doi.org/10.21165/gel.v77i2.2855

Submetido em: 29/06/2020 | Aceito em: 24/07/2020. 